\title{
Cross-Breed Abutments Dressed in Hybrid Denture Non-Coping, Coping and Post Space - Case Series
}

Mohammad Arif Lone', Syed Mohammad Noorani², Raman Ranauta ${ }^{3}$, Abhishek Avasthi ${ }^{4}$

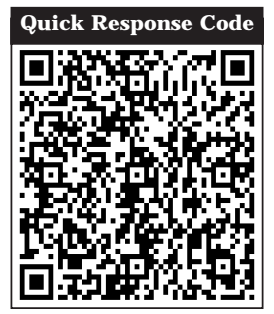

doi: $10.5866 / 2015.7 .10273$

${ }^{1}$ Registrar

Sheri-i-Kashmir Institute of Medical Sciences

Bemina Srinagar

2Senior Lecturer

Deptt. Of Prosthodontics Mansarovor Dental College Bhopal

${ }^{3}$ P.G Student

Swami Devi Dyal Hospital \& Dental College

Panchkula Haryana

${ }^{4}$ Senior Lecturer

Rayat Bahara Dental College \& Hospital

Mohali Punjab

\section{Article Info:}

Received: October 11, 2015

Review Completed: November 10, 2015

Accepted: December 9, 2015

Available Online: March, 2016 (www.nacd.in)

(C) NAD, 2015 - All rights reserved

\section{Email for correspondence:}

mohammadariflone@gmail.com

\begin{abstract}
:
Hybrid dentures uses one or more modified natural teeth for support, stability and retention of the prosthesis. ${ }^{1}$ it is apt to use the term crossbreed abutments as the denture is supported by teeth that range from reduced natural tooth to custom made support within the tooth by post space or natural tooth supported by external metal covering. In convention hybrid denture the crown of teeth are reduced to nearly above the ridge and the exposed tooth is covered with metallic cap over which the denture is fabricated. ${ }^{2}$ In case of access post retained biologic denture the post is placed within the root of retained teeth and denture is fabricated over the post. This not only increases retention, stability and support besides gives access to periapical areas for any treatment if needed. ${ }^{3}$
\end{abstract}

Key words: Edentulism, Overdenture, Non-coping, Coping, Attachments, Access Post

\section{Introduction:}

Teeth are very important not only to perform the various functions but they also maintain the profile of patient and preserve the alveolar bone. Loss of teeth leads to resorption of the alveolar process and decrease in thealveol ar bone length and volume. ${ }^{1-4}$ Bone is the foundation of support for the prosthesis, a multitude of factors affect bone however none more than the teeth. 5,6 The basic function of maxillary and mandibular arches is to support teeth; thus when teeth are lost, bone is lost. ${ }^{7}$, ${ }^{8}$ Telescope Dentures, Overly Dentures, Hybrid 
dentures, Overdentures are some of the synonym names used to describe tooth supported/assisted overdentures. Studies have shown that removal of teeth and wearing of complete denture generally results in loss of alveolar bone. Tallgren found bone loss is four times more common in mandible than maxilla over a period of 7 years. ${ }^{9,10}$

To overcome the increased loss of alveolar bone in partially edentulous areas, natural teeth can be used as an additional support for the prosthesis. Ledger encouraged leaving "Stumps" under artificial teeth. Tooth supported overdentures should be considered in every cases as an alternative to extraction of all natural teeth and they may be used instead of restorative procedures, such as fixed or removable partial dentures. ${ }^{11}$ Preserved and prepared root stumps for conventional overdentures add to the benefits of the complete denture. Retention of natural teeth for overdentures preserves some of the sensory input from periodontal receptors which are more precise than that obtained from the oral mucosa and the Sensory innervations is important components of mastication. Tooth mobility is also reduced when the tooth was preserved and reduced in height; the mobility was reduced from 100 to $60 \%$. Overdentures patients had shown better chewing efficiency ( $1 / 3$ higher) than the complete denture patient and the most important reason to preserve the tooth is that it ultimately preserves the alveolar bone heath and volume. ${ }^{12,13}$

\section{Case Report 1:}

A 60 year old man reported with the chief complaint of difficulty in mastication, on clinical examination revealed presence of few remaining maxillary and mandibular teeth. Teeth present in the upper arch were 16, 21, 24, 26 and in the lower arch the teeth present were 33, 34 (Figure 1). The teeth present in the said case can adjunct retention by providing triangular support to the prosthesis (Figure 2). During treatment planning it was decided to preserve all the remaining natural teeth and prepare them as abutments for the denture to make a conventional overdenture which will add to the retention, stability $\&$ support of the prosthesis. Diagnostic casts were prepared and were mounted, which made known adequate clearance of the teeth. Treatment planning was decided and was explained to the patient who wanted not to get extracted any more teeth and the patients consent was taken into consideration which included first endodontic preparation of the teeth followed by Prosthodontic rehabilitation.

In the first phase all the remaining natural teeth were endodontically treated and amalgam plugs were placed over the obturated canals to seal the canals. After endodontic treatment teeth crowns were reduced in the height $1 \mathrm{~mm}$ above the gingival height.

The Prosthodontic rehabilitation of the patient was initiated by making primary impression with irreversible hydrocolloid impression material. Wash impression was made with vinyl silicone. J aw relation was recorded and teeth arrangement was done keeping in consideration the position of abutment teeth. Followed by try in of the patient and processing of the denture. The overdenture was checked for occlusion within the oral cavity (Figure 3). ${ }^{14}$ Overdenture was delivered to the patient (Figure 4) and the denture had increased retention, stability and support.

\section{Case Report 2:}

A 57 year old male reported with the chief complaint of inability to chew. On clinical examination it was found that his teeth were missing from upper right and left posterior side and lower two central incisors were missing. The upper arch has present only four teeth comprising of two central incisors lateral and canine of left side (Figure 5). The patient wanted to preserve the remaining upper teeth so it was decided to make overdenture over the remaining teeth of upper arch. The treatment procedure was well explained to the patient in advance comprising of endodontic and Prosthodontic rehabilitation.

Teeth were first treated endontically this was followed by preparation of the abutments to place copings over them. Metal coping were placed over the prepared teeth to decrease the influences of caries attack on the remaining reduced tooth structure (Figure 6). ${ }^{15}$ The denture was constructed 


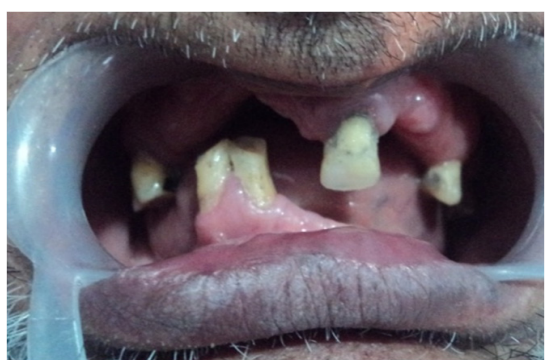

Figure 1: Partially Edentulous Patient

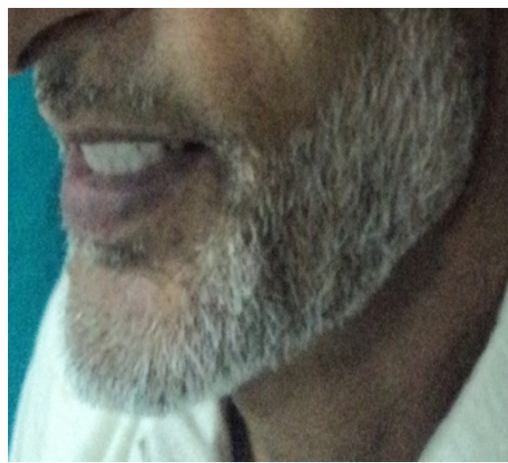

Figure 4: Post- Insertion

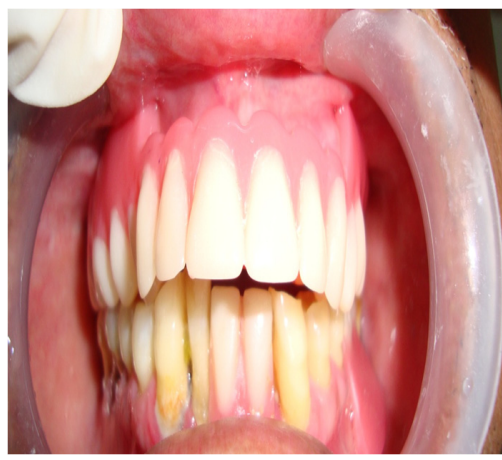

Figure 7: Overdenture Insertion

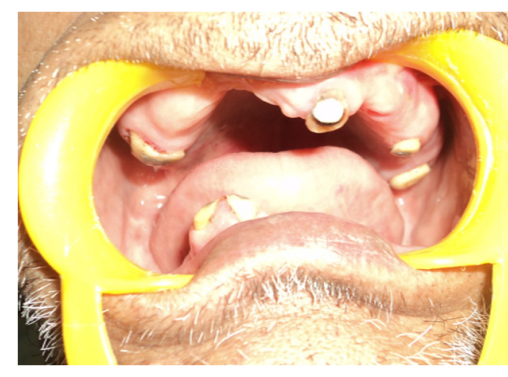

Figure 2: Triangular support of Abutments

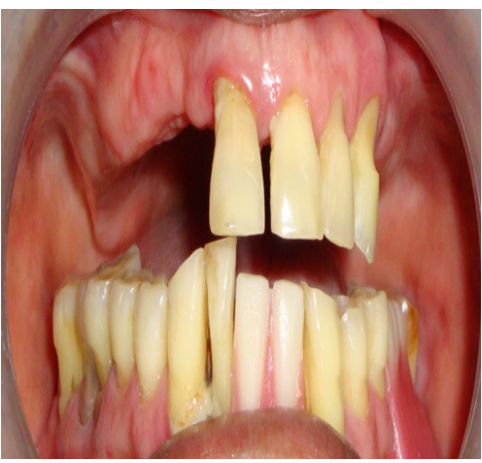

Figure 5: Retained Teeth

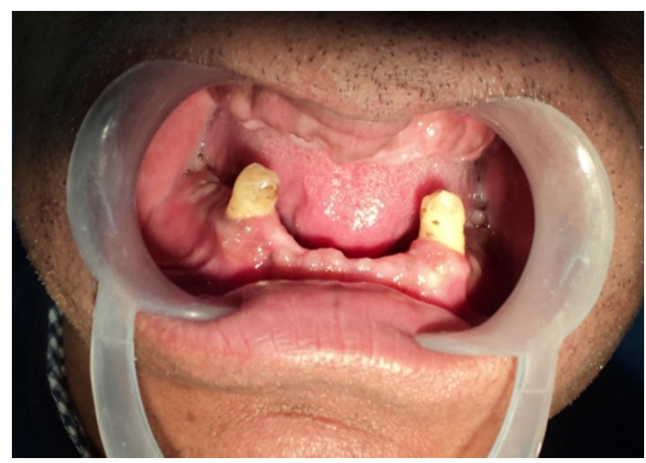

Figure 8: Retained Teeth

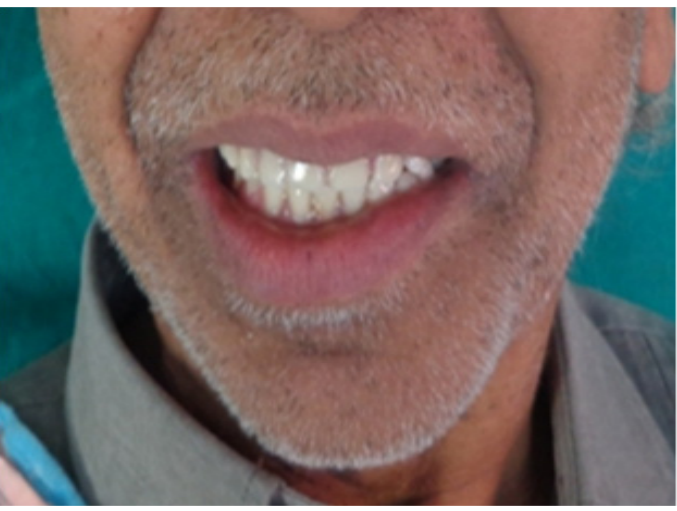

Figure 10: Post Insertion

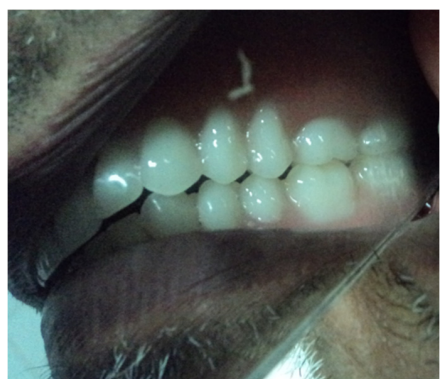

Figure 3: Checking Occlusion

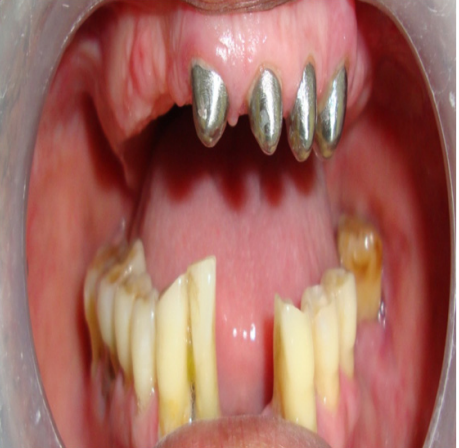

Figure 6: Metal Coping Abutments

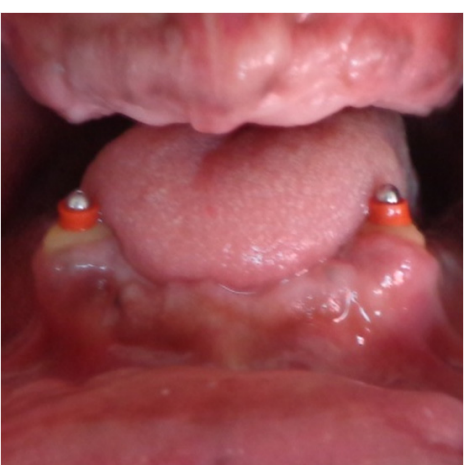

Figure 9: Rubber band on Post 
in conventional manner keeping in view the prominence of abutments. Overdenture abutments were relieved by hollowing the acrylic resin teeth with acrylic bur until the teeth were properly positioned over the abutments and occlusion checked. During try - in appointment the following things were taken into consideration ${ }^{16}$

\section{1- J aw Relation record were verified \\ 2- Aesthetic were checked \\ 3- Phonetic Verified}

After try in, the denture was processed, polished and finished. The processed denture was delivered to the patient that showed increased retention and stability (Figure 7).

\section{Case Report 3:}

A 60 year male with chief complaint of inability to chew and aesthetic deficiency .On clinical examination it was found that maxillary arch was completely edentulous and only one tooth was present in the mandibular arch per quadrant. The tooth present were 34, 44 in the mandibular arch (Figure 8). The benefit of retaining the remaining two natural teeth in the mandibular arch were explained to the patient and treatment plan was according decided in consent with the patient. So an overdenture was decided for the mandibular arch and a conventional denture for the maxillary arch was planned.

Treatment plan consist of endodontic procedure followed by prosthetic rehabilitation. Endodontic treatment was completed followed by reducing up to $1 \mathrm{~mm}$ above the gingival height and measuring the post length while leaving 3-4mm of apical Gutta Percha in the canal. Gutta Percha was removed with pesos reamers. Primary reamer was used o prepare the full length of post followed by preparing the countersink drill to create the flange and second tier preparation. Trail of the access post EDS (Essential Dental System) was done to ensure proper fit of the post. The post space created canal was etched and resin cement was used for luting the EDS post within the canal, excess cement if any was removed.

This was followed by prosthetic rehabilitation of the patient. Primary and wash impression of both the arches was made followed by J aw relation and try in. A well polished processed denture was prepared for insertion. Rubber bands were positioned to cover the height of contour of the post ball (Figure 9). The nylon female caps were placed on globe of post. Marking paste was placed on the cap and denture inserted over the ball post. Denture was removed, relieved in the area of marking paste to make space for nylon cap. Pink cold cure acrylic resin was placed in the relieved area. Denture was seated in the oral cavity and patient was instructed to close in centric occlusion. This was followed by removing the denture along with pick up attachment cap present on the inner surface of denture. The rubber band was removed and the excess if any was trimmed and inserted to the patient (Figure 10).

The access post retained denture not only helps in achieving the primary goals of an overdenture, besides, it acts as passive post that provides necessary strength, retention and stability a restoration requires. As the name says, it also gives access to the periapical tissues and ability to retreat if they get infected post-treatment, providing a much predictable overdenture treatment option.

\section{Conclusion:}

Modern techniques of preventive dentistry allow the dentist to restoreand retain virtual ly all natural teeth to serve as prosthetic abutments. Overdenture is a preventive dentistry concept which has been brought into prosthodontics. ${ }^{17,18}$

In partially edentulous patient it is utmost important to preserve the remaining natural teeth as they have direct influence on the ridge. ${ }^{19}$ It has been found that overdenture patients have chewing efficiency $1 / 3$ higher than complete denture patients. ${ }^{20}$ Partially edentulous patients have the feeling of proprioception through the remaining teeth even the presence of few natural teeth has strong psychological values for some patients. The overdenture abutments minimize the horizontal torquing forces on the denture and improve the stability and retention of denture. Retained overdenture abutments inhibit the rapid loss of alveolar bone. The prognosis of the restoration is likely to be influenced by numerous factors like Selection of patient, Treatment planning, 
Preparation of mouth, Execution of Prosthodontic work and maintenance

Finally it is reasonable to conclude that the retention of a part of the natural dentition offer the overdenture patient a gain in neuromuscular performance thereby giving him an edge over his edentulous counterpart

\section{References:}

1. Brewer A.A: The tooth supported denture. J Prosth Dent 30; $703: 1973$

2. Lord J S and Teel S. The Overdenture: patient selection, use of copings, and follow up evaluation. J Prosth Dent 1974; 32:41.

3. Cohen BI, Musikant BL, Deutsch AS: Clinical use of access post system. Dent Today 1998; 17:120-21

4. CrumR and Rooney G. Alveolar bone loss in overdentures: A five year study. J Prosth Dent 1978; 40:610.

5. Atwood DA. Some clinical factors related to the rate of resorption of residual ridge. J Prosth Dent 1962; 12:411450.

6. Atwood DA. Reduction of residual ridges: A major oral disease entity. J Prosth Dent 1971; 26:266-279.

7. Lammie GA. Reduction of the edentulous ridges. J Prosth Dent 1960; 10:605-611.

8. Sobolik CF. Alveolar bone resorption. J Prosth Dent 1960; 10:612-619.

9. Tallgren A. Alveolar boneloss in denture wearers are related to facial morphology. Acta odontol scand 1970; 28:251-270.
10. Tallgren A. The continued reduction of residual ridge in complete denture wearers: A mixed longitudinal study covering 25 years. J Prosth Dent1972; 27:120-132.

11. J erge CR. Comments on innervations of teeth. Dent Clin North Am 1965; 9:117-127.

12. Lovdal A, Schei O, Waerhaug J et al. Tooth mobility and alveolar bone resorption as a function of occlusal stress and oral hygiene. Acta Odontol Scand 1959; 17:61-75.

13. Renner RP, Gomes BC, Shakun ML et al. Four year longitudinal study of the periodontal health status of overdenture patients. J Prosth Dent 1984; 51:593-598.

14. Winkler Sheldon: Essentials of complete denture prosthodontics $2^{\text {nd }}$ edition.

15. Carlson et al. Prosthoddontic treatment for edentulous patients $10^{\text {th }}$ edition.

16. Rahn A.O. Textbook of complete denture $5^{\text {th }}$ Edition.

17. Kotwal K R. Outline of standards for evaluating patients for overdentures. J Prosth Dent 1977; 37:141.

18. Bolouri A. Prosposed treatment sequence for overdenture. J Prosth Dent 1980; 40(3):247-251.

19. J ain DC, Hegde V, Aparna I,Dhanasekar B. Overdenture with accesspost system: A clinical report. Int J Dent Res 2011; 22(2):359-361.

20. Tallgren A. The continuing reduction of the residual alveolar ridge in complete denture wearers: a mixed longitudinal study covering 25 years. J Prosth Dent 1972; 27(2):120.

\section{Gain quick access to our journal online View our journal at www.nacd.in}

